\title{
The Influence of Knowledge on Overconfidence: Consequences for Management and Project Planning
}

\author{
Golo Fabricius $^{1} \&$ Marion Büttgen ${ }^{1}$ \\ ${ }^{1}$ Institute for Marketing \& Management, Hohenheim University, Germany \\ Correspondence: Golo Fabricius, Institute for Marketing \& Management, Chair in Corporate Management \\ (570B), Hohenheim University, 70593 Stuttgart, Germany. E-mail: golo.fabricius@uni-hohenheim.de
}

Received: March 4, 2013

Accepted: March 22, 2013

Online Published: May 16, 2013

doi:10.5539/ijbm.v8n11p1

URL: http://dx.doi.org/10.5539/ijbm.v8n11p1

\begin{abstract}
Many challenging decisions are made under uncertainty, forcing managers to judge situations without in-depth knowledge of details or potential future outcomes. Earlier research shows that people tend to be overconfident about the accuracy of their judgments and comparatively optimistic about their future prospects, which means that people believe that they are more likely than others to experience positive events and less likely to suffer negative ones. Managers are likely to make decisions based on overconfident judgments and overly positive assessments of potential outcomes. In this study, we show that overconfidence is higher when little task-specific knowledge is available, which increases the likelihood of making incorrect decisions when faced with low knowledge. In a second step we investigate individual differences in overconfidence, whereby a cluster analysis reveals different behavioral patterns among participants (117 students) with low task-specific knowledge. Two main groups emerge among those with low task-specific knowledge. People characterized by low comparative optimism acknowledge their lack of knowledge and consequently exhibit little overconfidence. The vast majority of participants with low task-specific knowledge, However, display strong overconfidence in the accuracy of their judgments. We propose that self-enhancement motives are a reason for this increased overconfidence. Decision makers must be aware of overconfident judgments and also consider individual differences in overconfidence in order to make the right decisions.
\end{abstract}

Keywords: overconfidence, comparative optimism, unrealistic optimism, knowledge, self-enhancement

\section{Introduction}

The uncertainty surrounding decisions often forces managers to make assumptions about the current situation or predict future developments. Project management in particular is rife with examples of exceeded budgets and timelines where managers failed to plan adequately (Buehler, Griffin, \& Ross, 1994; Keil \& Robey, 1999; Lawrence \& Scanlan, 2007): A survey of KPMG Canada concerned with failure in IT-projects surveyed 1,450 public and private sector organizations and found that $92 \%$ of smaller projects with a planned completion time of under one year overran the schedule by more than $30 \%$ while this was the case for $86 \%$ of the larger projects (Whittaker, 1999). These inaccuracies in project planning indicate that several biases might reduce the reliability of estimates. For example, the desirability of the outcome might influence future expectations (Krizan \& Windschitl, 2007; Marks, 1951), wishful thinking might bias the source selection (Barber, Gordon, \& Franklin, 2009), and pessimistic scenarios might be disregarded when estimating future developments (Newby-Clark, Ross, Buehler, Koehler, \& Griffin, 2000). This study focuses on the bias of overconfidence, which refers to a person's unrealistically positive self-assessment of his or her accuracy in estimations. Such a biased assessment causes estimates to seem more reliable than they actually are. Overconfident managers who in turn rely on potentially overconfident employees might be a reason for the overly optimistic planning which becomes obvious in various projects. In this study we examine the influence of task-specific knowledge and comparative optimism on overconfidence.

\section{Framework}

\subsection{Overconfidence and Comparative Optimism}

Overconfidence is a well-established concept in literature (e.g., McKenzie, Liersch, \& Yanic, 2008; Teigen \& Jørgensen, 2005; Tsai, Klayman, \& Hastie, 2008). Moore and Healy (2008) analyzed studies on overconfidence 
and found three main types. The first, most commonly studied type is overestimation, in which people overestimate their actual ability, performance, or level of control. The second type is overplacement, in which people rank their abilities or performance higher than that of others. The third type is overprecision, which refers to people's unrealistically positive self-assessment of their accuracy in estimations. The focus of this article is on overprecision, although the more common term overconfidence is used.

In this study, we measure overconfidence through interval estimates: participants are asked to provide a numerical interval estimate in which they are $\mathrm{X} \%$ sure that the correct answer to the stated question lies in this interval. They exhibit overconfidence when this interval estimate contains the correct answer less than X\% of the time. To reach a given confidence level of X\% accuracy, participants need to adjust their interval estimate according to their task-specific knowledge: the lower the participant's task-specific knowledge, the wider the interval needs to be. Consequently, in the case of unbiased participants, higher knowledge reduces the span of the interval estimates made. Participants commonly choose their interval estimates far too narrowly; for a $90 \%$ confidence interval ("Give the answer such that you are 90\% sure"), the estimated ranges contain the correct answer, on average, less than $50 \%$ of the time (Moore \& Healy, 2008).

Individual characteristics are likely to influence the degree to which a person is overconfident. This study investigates if overconfidence occurs more often among people who exhibit high comparative optimism, i.e., the belief that they are more likely than others to experience positive events and less likely to suffer negative ones. Comparative optimism is also a well-established finding (Chambers, Windschitl, \& Suls, 2003; Hoorens, Smits, \& Shepperd, 2008; Weinstein, 1980). For example, Weinstein (1980) investigated people's tendency to be comparatively optimistic about future life events and found that for 42 events, students rated their own chances as above average for positive events and below average for negative events.

Comparative optimism was found to depend both on the characteristics of future events as well as on individual differences (Harris, Griffin, \& Murray, 2008). Analyzing seven samples with a total of 1,436 participants, Harris et al. (2008) found comparative optimism to be present for virtually all individuals and events. Higher perceived controllability of a negative event led to higher comparative optimism, while comparative optimism decreased for severe negative future events.

\subsection{The Role of Knowledge and Self-Enhancement}

Self-enhancement "refers to people's desire to enhance the positivity or decrease the negativity of the self-concept" (Sedikides \& Strube, 1995, p. 1330). Krueger (1998, p. 505) defined the self-enhancement bias as the "tendency to describe oneself more positively than a normative criterion would predict." The desire to maintain a positive self-concept (Sedikides \& Strube, 1995) can be targeted at the individual itself (the self-view of a person) or at external recipients. A positive self-description (Krueger, 1998) seems to be mainly oriented towards an external audience. Self-enhancement might trigger overconfidence: When making overconfident judgments, participants might choose narrower intervals in estimates, not because they believe such intervals are appropriate for their level of knowledge, but rather as a way of pretending they have more knowledge than they actually do.

When people adjust their self-presentation with the intent of presenting themselves in a favorable manner, they apply what is referred to as impression management strategies (Turnley \& Bolino, 2001). Self-promotion and other impression management strategies have been found to be most prevalent among individuals scoring high in self-monitoring. High self-monitors observe and control their expressive behavior and self-presentation, and are particularly sensitive about social appropriateness (Lennox \& Wolfe, 1984; Snyder, 1974; Snyder \& Gangestad, 1986), while being more effective in managing their social exchange relations (Flynn, Reagans, Amanatullah \& Ames, 2006).

In addition to personal characteristics, situational factors are likely to promote the application of impression management strategies. Self-enhancement is strongest in situations in which people perceive a potential threat to their self-concept (Sedikides \& Strube, 1995), which indicates that impression management strategies might also be applied to serve the purpose of self-enhancement. Participants with little task-specific knowledge might be reluctant to admit their lack of knowledge, preferring instead to present themselves as knowledgeable individuals. Because admitting a lack of knowledge can be perceived as a threat to their self-concept, participants will, in accordance with self-enhancement mechanisms, conceal this lack of knowledge by choosing a too narrow interval.

The business world in particular provides ample opportunity for the strategy of making overconfident estimates to be applied. Imagine, for example, a manager receiving information about expected sourcing costs for a new production line from two employees. Employee A makes an unbiased estimate, choosing an appropriately wide 
interval, while Employee B is overconfident and therefore chooses a narrow interval. Without any additional information, the manager will probably attribute higher knowledge to Employee B as he or she exhibits a higher level of certainty. Ironically, the overconfident Employee B is more likely than Employee A to give incorrect information. This, however, will not affect Employee B negatively, as long as the answer cannot be verified, i.e. the new production line is not actually sourced. Instead, Employee B succeeds in promoting an overly positive self-presentation and, at least in the short term, is considered more knowledgeable than Employee A.

\section{Hypotheses}

As discussed previously, people might use overconfident estimates as an impression management strategy when a person perceives a threat to his or her self-concept (Sedikides \& Strube, 1995). We therefore propose that people with knowledge deficits are more likely to apply overconfident interval estimates as an impression management strategy. Thus hypothesis 1 is that low task-specific knowledge increases overconfidence.

When people exhibit comparative optimism, they describe their future prospects in an unrealistically positive manner. Many of those future prospects are linked to people's success in life, such as receiving a high starting salary or owning a house (see Kruger \& Burrus, 2004; Weinstein, 1980). A higher degree of perceived influence on such events increases comparative optimism (Harris et al., 2008), which indicates that people also are likely to overestimate their skills and talent as a foundation of their future success when exhibiting comparative optimism. This positive self-assessment is likely to be closely related to a biased assessment of their own accuracy in making estimates, i.e. overconfidence, as the ability to make accurate estimates depends on one's personal capabilities. Thus hypothesis 2 is that comparative optimism increases overconfidence.

\section{Method}

\subsection{Sample Characteristics}

We conducted the study at the Carl-Theodor-Schule, a specialized business high school in Schwetzingen, Germany. In total, 176 students received questionnaires; we excluded incomplete questionnaires or those that have not been taken seriously. This was the case when for example structural patterns were marked instead of answering the questions. The remaining sample included 117 students, for a response rate of $66.5 \%$. Of these, 59 were men, and the ages ranged from 15 to 21 years $(M=17.2, S D=0.96)$. Participation was mandatory, as students performed the task in class during regular class hours. The duration of the study was approximately 30 minutes. All materials used were written in German.

\subsection{Procedure}

Participants were instructed to answer all questions without help from others and were informed that the questionnaires would be treated anonymously. After this introduction, their comparative optimism was assessed, followed by the measure for overconfidence, which contained 20 general knowledge questions about when historical events took place. Participants were instructed to provide a time range such that they were $80 \%$ sure that the correct date would lie in this range. At the end of the study, we collected demographical data consisting of age, sex, self-reported average grades at school, and self-reported grades in history.

\subsection{Assessments and Measures}

\subsubsection{Overconfidence}

We measured overconfidence in interval estimates by instructing participants to provide a time range such that they were $80 \%$ sure that the correct answer to the stated question lies in this interval. When less than $80 \%$ of the correct answers are included in the selected intervals, participants can be said to exhibit overconfidence. A lower hit rate consequently signifies higher overconfidence. The structure of each question (e.g., "When did Mark Zuckerberg found the social network 'facebook'?") was simple to avoid misunderstandings.

Interval estimates are widely used in project management, which we confirmed by surveying 27 companies from various industries that make extensive use of project management. Almost all companies (25) used historical project data from similar projects to plan task-completion times. The second common method was to apply interval estimates, which was used by 13 companies (48\%). 11 companies $(40 \%)$ at least partially determine completion times by estimating an upper time-limit which should not be overrun in e.g. $80 \%$ of the cases. Only eight companies (30\%) at least partially use single point estimates to determine task completion times, the single point being the expected completion time. We chose a confidence level of $80 \%$ as this appeared to be most commonly used in project management. The common use of interval estimates supports the validity of our measure for overconfidence in a business context. 


\subsubsection{Task-Specific Knowledge}

The average deviation between the arithmetical mean of the estimated interval and the true value (i.e., the year when the particular event took place) of all 20 questions answered by a participant represents the task-specific knowledge of that participant; a small deviation indicates a high level of knowledge, and a large deviation indicates a low level of knowledge. In short, if the mid-point of an interval estimate comes close to the actual year in which an event happened, the participant is considered to have high task-specific knowledge.

\subsubsection{Comparative Optimism}

We take a two-dimensional view of comparative optimism. We measure the first dimension using participants' expectations of experiencing five positive future events and the second dimension using their expectations of experiencing five negative future events. Participants were first asked to estimate the likelihood of experiencing the events themselves and then to estimate the likelihood that a comparable student of the same age, gender and school grades would experience the events, on a 7-point scale ranging from 0 (very unlikely) to 6 (very likely). We calculated the comparative optimism score separately for positive and negative items by subtracting the average expectation for the others from the average expectation for the self. Negative items were reversed before calculation. Consequently, a positive comparative optimism score indicates that participants expect more positive or less negative events to happen to them than to others.

The items measuring comparative optimism were selected from the studies of Weinstein (1980), Hoorens (1995), and Kruger and Burrus (2004). For comparative optimism about positive future events, Cronbach's alpha was .73 , and the factor analyses revealed only one factor. For comparative optimism about negative future events, Cronbach's alpha was .59. To improve scale reliability, we deleted two items by gradually removing items that correlated least with the other items. This process resulted in a Cronbach's alpha of .66. The items are listed in Table 1.

\subsubsection{School Grades}

The students were asked to report their overall average grades at school as well as their average grades in history. Participants were given the option not to answer these questions because forced answers can lead to biased reports, even in an anonymous setting. Only a few participants chose not to provide information about their grades. It was not possible to obtain any data on grades directly from the school because of privacy regulations.

We used grades in history to test the reliability of the measure of task-specific knowledge. The overall grades helped us assess whether students with high task-specific knowledge in history were also better students in general.

\section{Results}

Overall, participants exhibited strong overconfidence in the accuracy of their answers; their interval estimates included the historical events only $28.25 \%$ of the time instead of $80 \%$ as requested. In addition, we expected comparative optimism for both the positive events ("Positive things are going to happen to me") and the negative events ("Negative things are not going to happen to me").

Indeed, for negative events, participants exhibited strong comparative optimism. They expected fewer bad things to happen to them than to other people of the same age and gender $(t=12.82, d f=116, p<.001,95 \% \mathrm{CI}$ $[1.41,1.92])$. For positive events, the opposite result occurred: participants expected fewer positive things to happen to them than to others in the future $(t=-4.036, d f=116, p<.001$, CI $[-0.73,-0.25])$. Table 1 displays the values for the items. We found a negative correlation between comparative optimism regarding positive and negative events $\left(r_{s}=-.453, d f=115, p<.001\right)$. People who were optimistic about experiencing less negative events than others also believed they would experience less positive events than others. In the "Discussion" section, we focus mainly on comparative optimism regarding positive future events; that is, more similarities should exist between expecting an overly prosperous future and being overconfident in one's abilities than between being overconfident and fearing experiencing negative events. 
Table 1. Items of the comparative optimism scales for positive and negative events

\begin{tabular}{|c|c|c|c|c|}
\hline \multirow{2}{*}{ Measure } & \multirow{2}{*}{$M(S D)$} & \multirow{2}{*}{$p^{\mathrm{c}}$} & \multicolumn{2}{|c|}{$95 \% \mathrm{CI}$} \\
\hline & & & $L L$ & $U L$ \\
\hline Live past 70 & $-0.82(1.98)$ & $<.001$ & -1.18 & 0.45 \\
\hline Like first full-time job & $-0.38(1.74)$ & .020 & -0.70 & -0.06 \\
\hline Maintain a good relationship with relatives & $-0.17(2.13)$ & .386 & -0.56 & 0.22 \\
\hline Own a house & $-0.20(1.79)$ & .237 & -0.52 & 0.13 \\
\hline First salary more than $€ 27,000$ & $-0.87(1.74)$ & $<.001$ & -1.19 & -0.55 \\
\hline Be involved in an airplane crash $^{a}$ & $0.53(1.37)$ & $<.001$ & 0.28 & 0.79 \\
\hline Catch the flu & $1.58(1.86)$ & $<.001$ & 1.24 & 1.92 \\
\hline Get fired from first full-time job & $1.63(1.73)$ & $<.001$ & 1.32 & 1.95 \\
\hline Get divorced $^{\mathrm{b}}$ & $1.79(1.89)$ & $<.001$ & 1.44 & 2.13 \\
\hline Regret 20 years of life $\mathrm{a}^{\mathrm{a}}$ & $1.35(2.06)$ & $<.001$ & 0.97 & 1.72 \\
\hline
\end{tabular}

Notes: Positive values indicate comparative optimism, and negative values indicate comparative pessimism. The items are calculated by subtracting the value of the expectations for the others from the value for the expectations for the self. Negative items are reversed before calculation. $\mathrm{CI}=$ confidence interval; $\mathrm{LL}=$ lower limit; $\mathrm{UL}=$ upper limit.

${ }^{a}$ Item excluded to increase scale reliability.

${ }^{\mathrm{b}}$ No differences between the sexes: ANOVA $\left(F(1,115)=.065, p=.80, \eta^{2}=0\right)$.

${ }^{\mathrm{c}}$ Level of significance to the test value of $0(d f=116)$.

People are overconfident according to our measure of overconfidence when they choose their interval estimates too narrow to contain $80 \%$ correct answers (Soll \& Klayman, 2004). Unbiased participants always have a hit rate around $80 \%$ regardless of their task-specific knowledge, because they succeed in adjusting their interval estimates according to this knowledge. A hit rate under $80 \%$, however, indicates overconfidence. Our participants were overconfident as they failed to adjust their interval estimates according to their task-specific knowledge: No significant correlation between task-specific knowledge and interval width emerged $\left(r_{s}=-.045\right.$, $d f=115, p=.629$ ). The first hypothesis was confirmed, as participants with low task-specific knowledge were significantly more overconfident than others: We found a significant, positive correlation between task-specific knowledge and the percentage of correct answers $\left(r_{s}=.357, d f=115, p<.001\right)$. The percentage of correct answers reflects the degree of overconfidence in a way that a higher percentage of correct answers signify a lower level of overconfidence (with a percentage higher than $80 \%$ even signifying underconfidence). The correlations between the main measures appear in Table 2.

Table 2. Summary of correlations

\begin{tabular}{|c|c|c|c|c|c|}
\hline Measure & 1 & 2 & 3 & 4 & 5 \\
\hline 1. C_optimism (positive) & - & $-.453 *$ & .069 & -.021 & .127 \\
\hline 2. C_optimism (negative) & $-.453 *$ & - & .018 & -.022 & .038 \\
\hline 3. Hit rate $\mathrm{a}^{\mathrm{a}}$ & .069 & .018 & - & $.624 *$ & .357 \\
\hline 4. Interval width & -.021 & -.022 & $.624 *$ & - & -.045 \\
\hline 5.Task-specific knowledge & .127 & .038 & $.357^{*}$ & .045 & - \\
\hline
\end{tabular}

Notes: Correlations were measured by the Spearman rank-order correlation $(N=117)$. C_optimism (positive) stands for comparative optimism about positive future events (C_optimism (negative): negative events).

${ }^{a}$ Gives the percentage of correct answers included in the interval estimates. A hit rate under $80 \%$ indicates overconfidence.

$* p<.001$.

Although we expected comparative optimism to influence overconfidence, no significant correlation emerged between comparative optimism and the measure of overconfidence, e.g., the percentage of correct answers ( $\left.r_{\text {spositive events }}=.069, d f=115, p=.457 ; r_{\text {snegative events }}=.018, d f=115, p=.845\right)$. Therefore, the second hypothesis was not confirmed. 
An analysis of variance (ANOVA) confirmed a positive relationship between grades in history and task-specific knowledge $\left(F(9,107)=2.14, p=.032, \eta^{2}=0.15\right)$. Using Eta-squared, $15 \%$ of the total variance of task-specific knowledge is accounted for by the grades in history. For the overall grades at school, ANOVA did not reveal a significant effect on task-specific knowledge, although $11 \%$ of the total variance of task-specific knowledge can be explained by the overall grades $\left(F(7,109)=1.917, p=.074, \eta^{2}=0.11\right)$. Nevertheless, a highly significant correlation exists between grades in history and overall grades at school $\left(r_{s}=.481, p<.01\right)$, confirming that high grades in history are related to high overall grades. This finding confirms the reliability of our measure of task-specific knowledge and further indicates that participants with high task-specific knowledge tend to be better students.

The results thus far call for further investigation regarding the influence of comparative optimism on overconfidence, and the effect of task-specific knowledge. We conducted a cluster analysis to assess individual differences between the members of different sub-groups in the sample. In contrast to the analysis of the whole sample, the cluster analysis allows for a detailed view of commonalities and differences between different groups in the data set (Tuma, Decker, \& Scholz, 2011). In the macro view, however, there is considerable risk that a small or mid-sized group's typical characteristics will be misinterpreted as "noise" without actually being assessed.

A cluster analysis mainly serves an exploratory function, because only vague assumptions exist about the location of the clusters before the analysis. We, however, consider it to be an inherent part of research not only to take one's confirmed hypotheses into account but also to investigate further regarding rejected hypotheses in order to create new knowledge and foster upcoming research.

\section{Cluster Analysis: Method}

For the hierarchical cluster analysis, we used the average linkage (within-group) method. This method agglomerates clusters so that the average distance within the newly built cluster is minimized. We did not use Ward's Minimum Variance method because we expected different cluster sizes, nor did we use k-means clustering: The number of clusters and the location of the seed points were unclear, leading to poor recovery performance for this method (Milligan, 1980). The average linkage (within-group) method ensures that the final clusters are as homogeneous as possible within the groups and as heterogeneous as possible between the different clusters. The Squared Euclidean Distance was the measure of distance. The variables comparative optimism (for both positive and negative events), average interval width (chosen in the estimation exercise), and task-specific knowledge (average deviation between the mid-point of the estimated interval and the true value) form the input of the cluster analysis. For better comparability, all variables were transformed into Z-values with a standard deviation of 1 and an average of 0 before the analysis.

Outliers can considerably bias the agglomeration of clusters (especially when squared measures are used) and therefore must be eliminated before conducting the cluster analysis. Seven participants were identified as outliers by the single linkage method (nearest neighbor) and consequently excluded from the cluster analysis (remaining $N=110$ ).

After applying the average linkage method to identify clusters, we determined the optimal number of clusters by using the test established by Mojena (Milligan \& Cooper, 1985; Mojena, 1977; Veerappa \& Letier, 2011) and the elbow method, revealing an optimum for a four-cluster solution. Then we tested the groups for homogeneity by dividing the standard deviations of all variables within a group by the standard deviations of the variables in the total data set. For all variables, the standard deviation within the clusters was lower than that in the total data set.

\section{Cluster Analysis: Results}

The clusters are ranked according to members' task-specific knowledge from high (Cluster 1) to low (Cluster 4). Members of Cluster 1 (19\% of the students) have high knowledge and display high comparative optimism; thus they perceive themselves as more likely to experience positive events in the future than others. This presumption is rational because better students have higher chances of "living a successful life", which as a category includes the majority of positive future events presented in comparative optimism scales (see Kruger \& Burrus, 2004; Weinstein, 1980).

Cluster 2 exhibits the lowest comparative optimism about positive future events. This cluster $(32 \%$ of the students) contains students with average or slightly-above-average knowledge. These students are actually pessimistic about their chances of experiencing positive events in the future. One possible explanation is that members of this cluster fear being less successful in life than others (in particular, members of the 
high-performance Cluster 1) and thus have negative expectations of positive future events. This means that low comparative optimism should also occur for clusters with below-average knowledge. However, this is the case only for a small group (Cluster 3, 6\% of the students) in the low-knowledge sector. The members of Cluster 4 ( $43 \%$ of the students) display relatively high comparative optimism about positive events, although the value is still negative ( -0.12 compared to an average of -0.48 in the whole sample). The differences in comparative optimism (about positive events) between members of clusters 3 and 4 are significant $(F(1,53)=4.07, p=.049$, $\left.\eta^{2}=0.07\right)$.

Logically, interval width must be adjusted according to participants' level of task-specific knowledge in order to contain $80 \%$ correct answers. Remarkably, interval width and task-specific knowledge were not correlated when considering the whole sample ( $\mathrm{rs}=-.045, \mathrm{df}=115, \mathrm{p}=.629)$. As Table 3 shows, members of Cluster 4 in particular chose very narrow intervals. This is noteworthy in that members of Cluster 4 have the lowest task-specific knowledge but the narrowest interval width, consequently achieving the lowest rate of correct answers in the sample.

Table 3. Cluster description

\begin{tabular}{|c|c|c|c|c|c|c|}
\hline Cluster & $N(\mathrm{~m}, \mathrm{f})$ & C_Opt Positive & C_Opt Negative & Interval Width & $\begin{array}{l}\text { Task-Specific } \\
\text { Knowledge }^{\mathrm{a}}\end{array}$ & Hit Rate ${ }^{b}$ \\
\hline 1 & $21(13,8)$ & $0.82^{* * 2,3,4}$ & $1.14^{* * 2}$ & $33.27^{* * 3}$ & $45.99^{* * 2,3,4}$ & $0.37^{* 2 ; * 4}$ \\
\hline 2 & $35(20,15)$ & $-1.64^{* * 1,4}$ & $3.12^{* * 1,3,4}$ & $33.89^{* * 3}$ & $68.84^{* * 1,4 ; * 3}$ & $0.29^{* 1,3,4}$ \\
\hline 3 & $7(4,3)$ & $-0.94^{* * 1 ; * 4}$ & $1.57^{* * 2}$ & $102.09^{* * 1,2,4}$ & $87.71^{* * 1 ; * 2}$ & $0.41^{* 2 ; * * 4}$ \\
\hline 4 & $47(18,29)$ & $-0.12^{* * 1,2 ; * 3}$ & $0.77^{* * 2}$ & $28.89^{* * 3}$ & $90.13^{* * 1,2}$ & $0.20^{* * 1,3 ; * 2}$ \\
\hline Total & $110(55,55)$ & -0.48 & 1.64 & 35.95 & 74.77 & 0.28 \\
\hline
\end{tabular}

Notes: The cluster number was assigned according to participants' knowledge. Positive values indicate optimism for comparative optimism. Interval Width, Task-Specific Knowledge, and Hit Rate come from the interval estimates. $N(\mathrm{~m}, \mathrm{f})=N(\mathrm{masculine}$, feminine), and C_Opt Positive stands for comparative optimism about positive future events (C_Opt Negative: negative events).

${ }^{a}$ Low numbers indicate high knowledge. Measured in average deviation between the arithmetical mean of the estimated interval and the true value.

${ }^{\mathrm{b}}$ Gives the percentage of correct answers included in the interval estimates. A hit rate under $80 \%$ indicates overconfidence.

${ }^{*} \mathrm{i} p<.05$, with $\mathrm{i}=1, \ldots, 4$, indicates significant differences in comparison to cluster $\mathrm{i}$.

${ }^{*} \mathrm{i} p<.001$, with $\mathrm{i}=1, \ldots, 4$, indicates significant differences in comparison to cluster $\mathrm{i}$.

Given the results of Cluster 4, we assessed the differences between this specific cluster and the remaining clusters using a one-way ANOVA. Cluster 4 is characterized by significantly higher comparative optimism about positive events (value of $\left.-0.12, F(1,108)=6.36, p=.013, \eta^{2}=0.06\right)$, significantly lower knowledge $(F(1$, $\left.108)=41.64, p<.001, \eta^{2}=0.28\right)$, significantly narrower intervals $\left(F(1,108)=6.83, p=.010, \eta^{2}=0.06\right)$, and significantly fewer correct answers $\left(F(1,108)=24.54, p<.001, \eta^{2}=0.19\right)$. For an overview of the significant differences between the individual clusters, please consider Table 3 .

Within the four-cluster solution, the differences between the strongly overconfident, low-performance Cluster 4 and the far less overconfident Cluster 3 are notable. Despite having a similar level of task-specific knowledge $\left(F(1,53)=0.09, p=.768, \eta^{2}=0\right)$, members of Cluster 4 gave significantly fewer correct answers $(F(1,52)=$ $\left.16.85, p<.001, \eta^{2}=0.24\right)$ and chose significantly narrower intervals $\left(F(1,52)=82.18, p<.001, \eta^{2}=0.61\right)$ than members of Cluster 3. As described previously, members of the strongly overconfident Cluster 4 also exhibited significantly higher comparative optimism (about positive events) than members of Cluster $3(F(1,53)$ $=4.07, p=.049, \eta^{2}=0.07$ ). The very large effect sizes of the cluster affiliation on correct answers and interval width indicate a fundamentally different behavior in confidence interval estimates between members of Cluster 3 and members of Cluster 4 . There are no differences in task-specific knowledge between the two clusters.

\section{Discussion}

The results show that participants exhibit high overconfidence in interval estimates, with lower task-specific knowledge increasing this effect. Participants were asked to choose their intervals wide enough to include $80 \%$ correct answers. As mentioned previously, the correct dates were only included $28.25 \%$ of the time, thus participants were strongly overconfident about their own accuracy in estimation. This is of high importance in business and project management context. Imagine a manager planning a project timeline with only three main 
tasks which have to be completed one after the other. Even for just these three tasks the likelihood that all individual tasks stay within the expected time frame is only $0.28^{3}=2.25 \%$ instead of $0.8^{3}=51.2 \%$, which would be achieved by an $80 \%$ confidence level.

As specific resources are often required for interdependent projects with overlapping demands (Vairaktarakis, 2003), nearly all deviations from the time schedule are linked to lower efficiency in resource allocation. In some situations resources might not be available on time when the project overruns schedule, which will again delay the project. Some resources also create fixed costs which occur regardless of usage. Additional complications occur when one considers agreements with external stakeholders such as customers. If, for example, a new production line is needed in order to be able to deliver to a customer, but this line is not ready at the agreed upon time, the customer will be likely to demand compensation for losses caused by this delay.

Overconfidence increases with decreasing task-specific knowledge. Participants with the highest knowledge deficits chose the smallest intervals (Cluster 4, see Table 3) and consequently also show the highest overconfidence with only $20 \%$ correct answers.

This has major practical implications for project management. To avoid strongly overconfident judgments, project-managers with high task-specific knowledge should be selected in order to reduce overconfidence bias. Project managers should also be advised to focus on the acquisition of project related knowledge and information, especially during the early stages of project management.

Nevertheless, for low-knowledge clusters, the cluster analysis suggests a split into a high-overconfidence and a low-overconfidence cluster. Consequently, a noticeable group (i.e., Cluster 3) of participants with low knowledge does not exhibit increased overconfidence. In addition, the split into a high- and a low-overconfidence cluster indicates that two coping strategies can be applied when insufficient knowledge is available. The first strategy, which Cluster 3 applies, is to acknowledge the lack of ability to give a precise (rather narrow) interval estimate. This leads to choosing a wide interval in order to still be able to reach an acceptable rate of correct answers. The second strategy is to hide the lack of knowledge while making a "best guess" by choosing a narrow interval estimate. The vast majority of participants (Cluster 4) in the low-knowledge sector chose to hide their uncertainty and provide a narrow confidence interval.

When measuring overconfidence, Pulford and Colman (1997) found that hard/easy questions had an effect on participants, causing them to exhibit underconfidence when answering easy questions and overconfidence when answering hard questions. As the level of knowledge required to answer easy questions is lower, the effect of overconfidence is likely to depend on participants' knowledge.

If the effect of overconfidence depends directly on participants' knowledge, experts should exhibit less overconfidence than non-experts. McKenzie et al. (2008), however, found similar levels of overconfidence in interval estimates for experts and non-experts when presenting questions related to information technology (IT) to IT professionals and university students with different majors. Although the mid-points of the intervals chosen by the IT professionals came closer to the true values, the hit rate (and thus the overconfidence) remained comparable: IT professionals chose narrower intervals than university students. It might be that both experts and students needed to cope with similar threats to their self-concepts and used overconfident estimates as an impression management strategy. Experts face higher expectations, which increase the threat to their self-concept, but also have higher knowledge, which eases the estimation task. Ultimately, they might feel a similar threat to their self-concept as the non-experts who face lower expectations but have limited expertise to ease the task.

The overconfidence exhibited in Cluster 4 could be considered a self-promotion strategy in which participants aim for a favorable self-presentation by hiding their lack of knowledge. This explanation for increased overconfidence is in line with the findings of Tyler \& Rosier (2009), who found that comparative optimism was linked to motivational efforts in self-presentation. Participants employed comparative optimism only if the circumstances involved little risk of being held accountable for the assessment. We would expect similar effects for self-promotion through overconfidence. In general, applying self-promotion is a double-edged sword, as the effects of applied self-promotion on competence ratings are unclear. Rudman (1998) found a positive effect on competence ratings, but a negative effect on social attraction (for female participants), while Wayne \& Liden (1995) found a negative indirect effect for self-promotion on competence ratings, but found the impression management strategy of ingratiation to increase competence ratings.

In this study we found a major effect of knowledge on overconfidence $\left(r_{s}=-.357^{*}\right)$. We put forward the idea that this overconfidence in the low-knowledge sector is caused by participants using overconfident estimates as a self-promotion strategy serving self-enhancement motives. In the present study, however, self-promotion was 
not included in the measures, which means that for this claim empirical proof is still required.

Contrary to what we expected, we found no significant correlation between comparative optimism and overconfidence. Expecting more positive things to happen to oneself compared to others does not generally lead to increased overconfidence in the accuracy of judgments. Nevertheless, among participants with low levels of task-specific knowledge, differences between the characteristics of members of cluster 3 (comparative pessimism and little overconfidence) and cluster 4 (considerably higher comparative optimism and high overconfidence) might indicate an influence of comparative optimism on overconfidence. It is important to note that this only seems to apply for low levels of task-specific knowledge.

When Weinstein (1980) first investigated people's tendency to be comparatively optimistic about future life events, he found that students rated their own chances as above average for positive events and below average for negative events. For managers comparative optimism means that they generally expect to achieve superior results compared to their peers, although this is not possible on a cumulative level (as the average can only achieve average results). This unrealistic optimism consequently leads to biased judgments of the likelihood of positive project outcomes that makes investments look more promising than they actually are. This is in line with the earlier finding that pessimistic scenarios are consistently rated less plausible than optimistic scenarios and are therefore usually not taken into account (Newby-Clark et al., 2000). Interestingly, in contrast with earlier findings (Fosnaugh, Geers, \& Wellman, 2009; Kruger \& Burrus, 2004; Weinstein, 1980), in this study we found comparative optimism for negative future events but comparative pessimism for positive future events. Future research could investigate whether managers are only comparatively optimistic regarding threats but not positive outcomes.

We found negative expectations for all positive future events tested (see Table 1, significant for three of five items), although previous research revealed comparative optimism for all the items (Kruger \& Burrus, 2004; Weinstein, 1980). Because our study is based on a sample with an average age comparable to previous studies, the only major difference is the cultural background of our sample (German as opposed to American). Indeed, several studies have investigated cultural differences in comparative optimism (Heine \& Lehman, 1995; Shuper, Sorrentino, Otsubo, Hodson, \& Walker, 2004; Rose, Endo, Windschitl, \& Suls, 2008). In these studies, the Western (Canada, United States) sample exhibited higher comparative optimism than the Eastern (Japanese) sample. A German sample might exhibit less comparative optimism than a US sample. Furthermore, people might actually not be comparatively optimistic about every type of positive future event but the socio-economic environment may have an impact on their comparative optimism.

The main finding of this study is that overconfidence, or the selection of overly narrow interval estimates, is strongest for people with low task-specific knowledge. A small group of participants, however, is able to perform a more realistic self-assessment about their estimation capabilities despite having low task-specific knowledge. This group exhibits little overconfidence and is characterized by negative expectations of experiencing positive future events. We conclude that people who are comparatively optimistic about their future prospects are more likely to be overconfident when little knowledge is available. In this case, overconfidence might serve as a self-promotion strategy in which people try to hide their lack of knowledge by indicating high levels of confidence in their estimates.

High complexity, long project completion times, the inability to compare projects due to their uniqueness, and large differences in resource allocation for different projects hinder empirical investigation in the project management area. Although this study reports noteworthy findings, there are some inherent limitations. The first limitation is that the sample of the study consists of students $(N=117)$ with an average age of 17.2 years. Even though they have been introduced to project management basics, they are not project management professionals and might behave differently, especially due to a lack of expertise and experience in project management planning. Secondly, the study was not conducted in a project management setting, but general measures were taken for the variables. One concern might be that the low external validity of the findings does not allow conclusions for project management settings.

Project managers have-similarly to students-been found to be strongly overconfident in interval estimates regarding task-completion times of the projects conducted in their company (Jørgensen, Teigen, \& Moløkken, 2004) while expertise has not been found to decrease overconfidence of IT-experts (McKenzie et al., 2008). Overconfidence has been confirmed, not only for project managers and IT-experts, but also among epidemiologists, public health experts, ecologists, and biologists (Speirs-Bridge et al., 2010). We therefore consider overconfidence to be a relatively stable effect both regarding the sample as well as the experimental setting, which supports the validity of our findings and the conclusions drawn with regard to project 
management. Employees with little task-specific knowledge are more likely to be strongly overconfident: Managers need to anticipate these overconfident judgments; otherwise, they run the considerable risk of making the wrong decisions.

\section{Acknowledgments}

We thank students at the Carl-Theodor-Schule for participating in our research and Gena Olson for her helpful and extensive comments on previous versions of this article.

\section{References}

Barber, S. J., Gordon, R., \& Franklin, N. (2009). Self-relevance and wishful thinking: Facilitation and distortion in source monitoring. Memory \& Cognition, 37, 434-446. http://dx.doi.org/10.3758/MC.37.4.434

Buehler, R., Griffin, D., \& Ross, M. (1994). Exploring the "Planning Fallacy": Why people underestimate their task completion times. Journal of Personality and Social Psychology, 67, 366-381. http://dx.doi.org/10.1037/1076-898X.6.3.171

Chambers, J. R., Windschitl, P. D., \& Suls, J. (2003). Egocentrism, event frequency, and comparative optimism: When what happens frequently is 'more likely to happen to me'. Personality and Social Psychology Bulletin, 29, 1343-1356. http://dx.doi.org/10.1177/0146167203256870

Flynn, F. J., Reagans, R. E., Amanatullah, E. T., \& Ames, D. R. (2006). Helping one's way to the top: Self-monitors achieve status by helping others and knowing who helps whom. Journal of Personality and Social Psychology, 91, 1123-1137. http://dx.doi.org/10.1037/0022-3514.91.6.1123

Fosnaugh, J., Geers, A. L., \& Wellman, J. A. (2009). Giving off a rosy glow: The manipulation of an optimistic orientation. Journal of Social Psychology, 149, 249-263. http://dx.doi.org/10.3200/SOCP.149.3.349-364

Harris, P. R., Griffin, D. W., \& Murray, S. (2008). Testing the limits of optimistic bias: Event and person moderators in a multilevel framework. Journal of Personality and Social Psychology, 95, 1225-1237. http://dx.doi.org/10.1037/a0013315

Heine, S. J., \& Lehman, D. R. (1995). Cultural variation in unrealistic optimism: Does the west feel more invulnerable than the east? Journal of Personality and Social Psychology, 68, 595-607. $\mathrm{http}: / / \mathrm{dx}$.doi.org/10.1037/0022-3514.68.4.595

Hoorens, V. (1995). Self-favoring biases, self-presentation, and the self-other asymmetry in social comparison. Journal of Personality, 63, 793-817. http://dx.doi.org/10.1111/j.1467-6494.1995.tb00317.x

Hoorens, V., Smits, T., \& Shepperd, J. A. (2008). Comparative optimism in the spontaneous generation of future life-events. British Journal of Social Psychology, 47, 441-451. http://dx.doi.org/10.1348/014466607X236023

Jørgensen, M., Teigen, K. H., \& Moløkken, K. (2004). Better sure than safe? Over-confidence in judgement based software development effort prediction intervals. Journal of Systems \& Software, 70, 79-94. http://dx.doi.org/10.1016/S0164-1212(02)00160-7

Keil, M., \& Robey, D. (1999). Turning around troubled software projects: An exploratory study of the deescalation of commitment to failing courses of action. Journal of Management Information Systems, 15, 63-87.

Krizan, Z., \& Windschitl, P. D. (2007). The influence of outcome desirability on optimism. Psychological Bulletin, 133, 95-121. http://dx.doi.org/10.1037/0033-2909.133.1.95

Krueger, J. (1998). Enhancement bias in descriptions of self and others. Personality and Social Psychology Bulletin, 24, 505-516. http://dx.doi.org/10.1177/0146167298245006

Kruger, J., \& Burrus, J. (2004). Egocentrism and focalism in unrealistic optimism (and pessimism). Journal of Experimental Social Psychology, 40, 332-340. http://dx.doi.org/10.1016/j.jesp.2003.06.002

Lennox, R. D., \& Wolfe, R. N. (1984). Revision of the self-monitoring scale. Journal of Personality and Social Psychology, 46, 1349-1364. http://dx.doi.org/10.1037/0022-3514.46.6.1349

Marks, R. W. (1951). The effect of probability, desirability, and 'privilege' on the stated expectations of children. Journal of Personality, 19, 332-351. http://dx.doi.org/10.1111/j.1467-6494.1951.tb01107.x

McKenzie, C. R. M., Liersch, M. J., \& Yanic, I. (2008). Overconfidence in interval estimates: What does expertise buy you? Organizational Behavior and Human Decision Processes, 107, 179-191. http://dx.doi.org/10.1016/j.obhdp.2008.02.007 
Milligan, G. W. (1980). An examination of the effect of six types of error perturbation on fifteen clustering algorithms. Psychometrika, 45, 325-342. http://dx.doi.org/10.1007/BF02293907

Milligan, G. W., \& Cooper, M. C. (1985). An examination of procedures for determining the number of clusters in a data set. Psychometrika, 50, 159-179. http://dx.doi.org/10.1007/BF02294245

Mojena, R. (1977). Hierarchical grouping methods and stopping rules: An evaluation. The Computer Journal, 20, 359-363. http://dx.doi.org/10.1093/comjnl/20.4.359

Moore, D. A., \& Healy, P. J. (2008). The trouble with overconfidence. Psychological Review, 115, 502-517. http://dx.doi.org/10.1037/0033-295X.115.2.502

Newby-Clark, I. R., Ross, M., Buehler, R., Koehler, D. J., \& Griffin, D. (2000). People focus on optimistic scenarios and disregard pessimistic scenarios while predicting task completion times. Journal of Experimental Psychology: Applied, 6, 171-182. http://dx.doi.org/10.1037//1076-898X.6.3.171

Lawrence, P., \& Scanlan, J. (2007). Planning in the dark: Why major engineering projects fail to achieve key

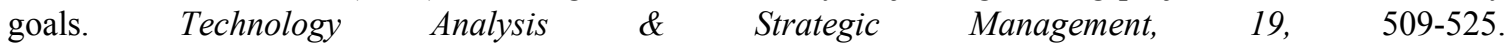
http://dx.doi.org/10.1080/09537320701403508

Pulford, B., \& Colman, A. M. (1997). Overconfidence: Feedback and item difficulty effects. Personality and Individual Differences, 23, 125-133. http://dx.doi.org/10.1016/S0191-8869(97)00028-7

Rose, J. P., Endo, Y., Windschitl, P. D., \& Suls, J. (2008). Cultural differences in unrealistic optimism and pessimism: The role of egocentrism and direct versus indirect comparison measures. Personality and Social Psychology Bulletin, 34, 1236-1248. http://dx.doi.org/10.1177/0146167208319764

Rudman, L. A. (1998). Self-promotion as a risk factor for women: The costs and benefits of counterstereotypical impression management. Journal of Personality and Social Psychology, 74, 629-645. http://dx.doi.org/10.1037/0022-3514.74.3.629

Sedikides, C., \& Strube, M. J. (1995). The multiply motivated self. Personality and Social Psychology Bulletin, 21, 1330-1335. http://dx.doi.org/10.1177/01461672952112010

Shuper, P. A., Sorrentino, R. M., Otsubo, Y., Hodson, G., \& Walker, A. M. (2004). A theory of uncertainty orientation-implications for the study of individual differences within and across cultures. Journal of Cross-Cultural Psychology, 35, 460-480. http://dx.doi.org/10.1177/0022022104266109

Snyder, M. (1974). Self-monitoring of expressive behavior. Journal of Personality and Social Psychology, 30, 526-537. http://dx.doi.org/10.1037/h0037039

Snyder, M., \& Gangestad, S. (1986). On the nature of self-monitoring: Matters of assessment, matters of validity. Journal of Personality and Social Psychology, 51, 125-139. http://dx.doi.org/10.1037/0022-3514.43.1.123

Soll, J. B., \& Klayman, J. (2004). Overconfidence in interval estimates. Journal of Experimental Psychology: Learning, Memory, and Cognition, 30, 299-314. http://dx.doi.org/10.1037/0278-7393.30.2.299

Speirs-Bridge, A., Fidler, F., McBride, M., Flander, L., Cumming, G., \& Burgman, M. (2010). Reducing overconfidence in the interval judgments of experts. Risk Analysis: An International Journal, 30, 512-523. http://dx.doi.org/10.1111/j.1539-6924.2009.01337.x

Teigen, K. H., \& Jørgensen, M. (2005). When $90 \%$ confidence intervals are $50 \%$ certain: On the credibility of credible intervals. Applied Cognitive Psychology, 19, 455-475. http://dx.doi.org/10.1002/acp.1085

Tsai, C. I., Klayman, J., \& Hastie, R. (2008). Effects of amount of information on judgment accuracy and confidence. Organizational Behavior and Human Decision Processes, 107, 97-105. http://dx.doi.org/10.1016/j.obhdp.2008.01.005

Tuma, M. N., Decker, R., \& Scholz, S. W. (2011). A survey of the challenges and pitfalls of cluster analysis application in market segmentation. International Journal of Market Research, 53, 391-414. http://dx.doi.org/10.2501/IJMR-53-3-391-414

Turnley, W. H., \& Bolino, M. C. (2001). Achieving desired images while avoiding undesired images: Exploring the role of self-monitoring in impression management. Journal of Applied Psychology, 86, 351-360. http://dx.doi.org/10.1037//0021-9010.86.2.351

Tyler, M. J., \& Rosier, J. G. (2009). Examining self-presentation as a motivational explanation for comparative optimism. Journal of Personality and Social Psychology, 97, 716-727. http://dx.doi.org/10.1037/a0016231

Vairaktarakis, G. L. (2003). The value of resource flexibility in the resource-constrained job assignment 
problem. Management Science, 49, 718-732.

Veerappa, V., \& Letier, E. (2011). Understanding clusters of optimal solutions in multi-objective decision problems. Requirements Engineering Conference (RE), 19, 89-98.

Wayne, S. J., \& Liden, R. C. (1995). Effects of impression management on performance ratings: A longitudinal study. Academy of Management Journal, 38, 232-260.

Weinstein, N. D. (1980). Unrealistic optimism about future life events. Journal of Personality and Social Psychology, 39, 806-820. http://dx.doi.org/10.1037/0022-3514.39.5.806

Whittaker, B. (1999). What went wrong? Unsuccessful information technology projects. Information Management \& Computer Security, 7, 23-29. 